\title{
The Function of Creativity on the Optimization of Innovation Management system
}

\author{
Fu Zhongbo ${ }^{1, a}$ Chen $\mathrm{yi}^{2, \mathrm{~b}}$ \\ ${ }^{1}$ Xiamen University. Xiamen City, China \\ ${ }^{2}$ Xiamen University. Xiamen City, China \\ aZZhongbo@sunyotech.com ${ }^{\mathrm{b}}$ chyionly@qq.com
}

Keywords: creative industry; innovation management; clusters

\begin{abstract}
For a long time, the innovation system is always closely linked with technological innovation rather than cultural creativity. The purpose of this paper is to analyze the function of the creative industry and clusters on the optimization of the innovation management system. Since there is little literature study on creativity and innovation, the study how creative industries function on the optimization of the innovation system provides a new perspective for the review between creativity and innovation.
\end{abstract}

\section{Introduction}

Having a sustainable competitive advantage is generally considered as the key to improve the welfare for a country. The most competitive advantage is the high rate of innovation nowadays. Innovation has become the dominant trend of modern economic development, and is considered to be the driving force of the growth. Many scholars believe that innovation plays a key role in economic development (Schumpeter, 1934; Kusiak, 2007). Once Gopalakrishnan and Damanpur(1997) pointed out that the functions of innovation include fostering economic growth, enhancing and maintaining the company's high-performance, building industrial competitiveness and improving people's living standards. Hauser et al. (2005) pointed out innovation is the important basis of competing in the global market. Innovation management system has become the theme in many economies such as BRIC (Brazil, Russia, India and China). However, for a long time, the innovation is always closely linked with technology rather than culture. The purpose of this paper is to analyze the role of the creative industry and clusters on the innovation management optimization.

\section{Creative Industry Support Innovation Management in Other Industries}

Bagwell (2008) pointed out that the creative industry is characterized high degree of individual skills and commitment, and often takes culture and creativity precedence over commercial returns. They are usually a carrier in a flexible, project team, and the entire creative industry are mainly formed by the dynamic SMEs. The creative industry is an industrial pattern with a strong focus on innovation and consumer demand (DCMS, 2007).

In developed countries, the creative industry is considered the most promising industry. In addition to promoting economic growth, the role on innovation management is another cause for concern.

Firstly, the economic behavior of the creative industry is to introduce and foster innovation, so it directly increases the output of the gains of innovation, including new products, new services, as well as process innovation like new technology or new procedures to improve product quality and productivity.

Secondly, the creative industry supports innovation in other industries through creative inputs. The input can be in the downstream chain, namely producing creativity and be applied to other industries. It also can be in the upstream chain, namely creative industry develops new demand of technology from other suppliers (such as technical producer). The creative industry's support for innovation is closely related to "open innovation", which often requires their own innovative 
resources combined with external inputs. The external inputs typically include external knowledge (technology) or professional R\&D services, generally from customers, suppliers, partners and competitors. As the best producers of intellectual property, creative industry is the most attractive sources of external input. It offers a variety of innovative services, including new creative ideas, product design and R\&D support, more efficient market strategy and engineering services.

Thirdly, a strong supply chain is convenient for the spread of creativity between creative industry and other industries. They found that the creative industry and other sectors of the economy also exist between the B2B important link, for more innovative companies, generally have the potential for product innovation.

Fourthly, an important effect of the creative industry for innovation management is to connect the academic and commercial fields. On the one hand, the creative industry employs personnel with knowledge that are mainly university graduates. On the other hand, the employment in the creative industry have close ties with the past mentors, professors and alumni, in order to transform scientific discoveries and methods into commercial fields more convenient.

\section{Creative Industry Clusters and Innovation Management System}

\subsection{Cluster and Innovation}

Michael Porter(1998) defined the cluster as "an associated chain linkages of enterprises, professional providers, service providers, affiliates and corporate collected in geographic". This collection is considered to have competitive advantage.

Organization for Economic Cooperation and Development (OECD, 1999) pointed out that the cluster is a management mechanism for the government to implement innovation policy. Therefore, cluster analysis is one of the main factors on innovation system. Diversity also exists between different clusters in innovative practice. Some clusters are closely linked with scientific system, depending largely on the findings of scientific innovations; some clusters play a intermediary role between other clusters (such as IT). There are some clusters independent from the outside of the scientific system (such as mechanical engineering). Therefore, OECD (1999) defines the cluster as: "a cluster is a network which consists of interdependent enterprises or institutions of knowledge production (universities, research institutes, technology companies), or bridging institutions for knowledge and customers (such as providing professional or consulting services), with the ability to create added value." Cluster is a significant feature of creative industry.

\subsection{Motives and characteristics of creative industry clusters}

Scott(2004) ${ }^{1}$ analyzes the reason why the creative industries in the spatial agglomeration trends. From the production point of view, the creative industries are of five major technical and organizational characteristics:

(1)A large number of labor demand for the skilled;

(2)The organization of production always strongly conducts through small and medium-sized companies to form a dense network;

(3)Their content of various industries stimulates the demand for a variety of talent;

(4)There are many foreign participations in the economy;

(5)The common wealth runs in the series, such as providing business-related incentives to support the flow of information, and promote trust and cooperation between the companies and so on.

Since the above five characteristics, creative enterprises show a strong correlation and spontaneous gathering. Then from the sales point of view, small local producers are more willing to join large companies controlled by the global sales network, the result extends a place closely associated with the global zone. Therefore, the creative industry will typically exhibit increasingly clear spatial concentration.

\footnotetext{
${ }^{1}$ Allen. J. Scott. Cultural-products Industries and Urban Economic Development: Prospectsfor Growth and Market Contestat. URBAN AFFAmS REVIEW, 2004(4).
} 


\subsection{Creative industry clusters and innovation management system}

The linkages between creative industry clusters and innovation system can be reflected through the following aspects:

(1) Education and Training. Creative industry clusters can achieve educational and training functions. Jaaniste(2009) pointed out that the creative industry and sectors can become innovative skills training institutions, the rich "creative curriculum" such as those on teamwork, dealing with the problem as well as cultural sensitivity, etc., make up the industry's lack of soft power.

(2) Science and R\&D. Creative industries can be seen as knowledge production sector, it is a research institution. It can produce new concepts, methods and material output. Combining creative industry and research has opened up new areas of research and development, thereby strengthening innovation systems.

(3) Participation in international world. Towards internationalization is an inevitable trend of modern economic development. Creative industry clusters as a part of global networks, compared to other traditional industries clusters, have more opportunities and ability to participate in international contacts, and establish an international innovation system integrated into the global network.

(4) Financing support. With a strong cultural compatibility, creative industry always conduct a series of cultural events such as display, which enables access to many cultural fund or financial support, so the creative industry helps support innovative financing.

(5) Creative environment. An important function of creative industry clusters is to create a creative environment to attract creative talents. Florida (2002) believes that creative environment is to take root and flourish creative ecosystems and habitats. Creative industries provide creative "climate" to attract and retain creative talent from home and abroad.

(6) Market conditions. Creative Clusters affect market conditions in many ways. As mentioned earlier, the clusters can improve competitiveness, employment growth and the formation of new companies. It provides new employment opportunities, attracting creative professionals in the region to promote the establishment of new enterprises, and vice versa have an impact on competition, suppliers and partners. In addition, the creative industry, can increase the overall aesthetic quality, to make products more attractive to customers. The creative input and marketing add value to their products, thus creating and increasing market demand of the product.

\section{Conlusion}

In a word, putting creative industries into the innovation management system, breaking the existing technology innovation centered innovation system, building innovation system with the dual function of technological innovation and cultural creativity helps to improve the function of the innovation system, promote the balanced development of the economy. Since there is little the literature study of creativity and innovation, the study of the role of creative industries on the optimization of the innovation management system provides a new perspective for the link between creativity and innovation.

\section{References}

[1] Allen.J.Scott,“Cultural-products Industries and Urban Economic Development: Prospectsfor Growth and Market Contestat”, URBAN AFFAmS REVIEW，2004， (4).

[2] Richard Florida etc.“The University and the Creative Economy”, 2006.

[3] Susan Bagwell,“Creative clusters and city growth”, Creative Industries Journal Volume1 Number1.2008.

[4] Creative Economy Report 2010.

[5] John Hartley, “Creative Industries”.First published 2005 by Blackwell Publishing Ltd. 